\title{
Computational Fluid Dynamics Study of Balloon System Tethered to a Stratosail
}

\author{
Jayakanth Loganathan ${ }^{1}$, Kian-Meng Lim ${ }^{2}$, Heow Pueh Lee ${ }^{3}$ and Boo Cheong Khoo ${ }^{4}$ \\ Department of Mechanical Engineering, National University of Singapore, Singapore, 117575
}

\begin{abstract}
In this paper, we present a numerical study of a stratospheric balloon system tethered to a passive device, known as the Stratosail, for station-keeping operation. For scientific applications, stratospheric balloons that operate at altitudes between 15 and $20 \mathrm{~km}$ will need to maintain station over a fixed point above the earth for a prescribed period of time. This is a challenging problem due to the limitation of payloads and lack of an energy source. The present study uses computational fluid dynamics (CFD) simulations to analyze the drift velocity of such a balloon-Stratosail system under typical wind conditions in the stratosphere. The Stratosail is attached below the super-pressure helium balloon via a long and thin tether about 10 to $15 \mathrm{~km}$ below the balloon, providing a drag force to alter the flight path of the balloon. Its operation depends on the natural differences in the wind speed and wind direction at different altitudes in the atmosphere that act on the balloon and the Stratosail (spaced far apart by $10 \mathrm{~km}$ to $15 \mathrm{~km}$ ). In this study, we calculated the drag forces on the balloon and Stratosail for typical wind speeds at various altitudes in the stratosphere. The tether was also modelled as a cable joining the balloon and sail. With this model, the drift velocity of the system was calculated for various altitudes and the angle of attack of the sail.
\end{abstract}

\section{Nomenclature}

$C_{d} \quad=\quad$ drag coefficient

$s \quad=$ tether length

$\mathrm{T}_{0} \quad=$ horizontal force in tether

$w \quad=$ weight per unit length of tether

$y \quad=$ vertical coordinate

$z \quad=\quad$ horizontal coordinate

\section{Introduction}

$\mathrm{T}$

HE Stratosail is part of a balloon guidance system designed to alter or control the flight path of balloon systems (Ref. 1). It makes use of the natural difference in wind speed at different altitudes in the atmosphere to reduce the drift of the system, thus providing a passive mode of control.

In this project, the dynamics of a stratospheric balloon system with a spherical super pressure helium balloon tethered to a stratosail is investigated. The super pressure helium balloon provides the buoyancy lift for the entire system, while the stratosail is attached at the other end of a long tether (typically $15 \mathrm{~km} \mathrm{long}$ ), as illustrated in Fig. 1.

The stratosail and the spherical balloon are at different altitudes, and in an ideal situation, the balloon and the stratosail will experience winds in opposing direction which will reduce the drift of the entire system. A series of parametric studies were conducted on various factors, such as balloon size, altitude difference, and the angle of orientation of the stratosail. The aerodynamic forces generated by the stratosail and the spherical balloon were investigated. With these forces, the steady-state drift velocity and the length of tether required are reported.

\footnotetext{
${ }^{1}$ Student, Mechanical Engineering, National University of Singapore, Singapore 117575.

${ }^{2}$ Associate Professor, Mechanical Engineering, National University of Singapore, Singapore 117575.

${ }^{3}$ Associate Professor, Mechanical Engineering, National University of Singapore, Singapore 117575.

${ }^{4}$ Professor, Mechanical Engineering, National University of Singapore, Singapore 117575.
} 


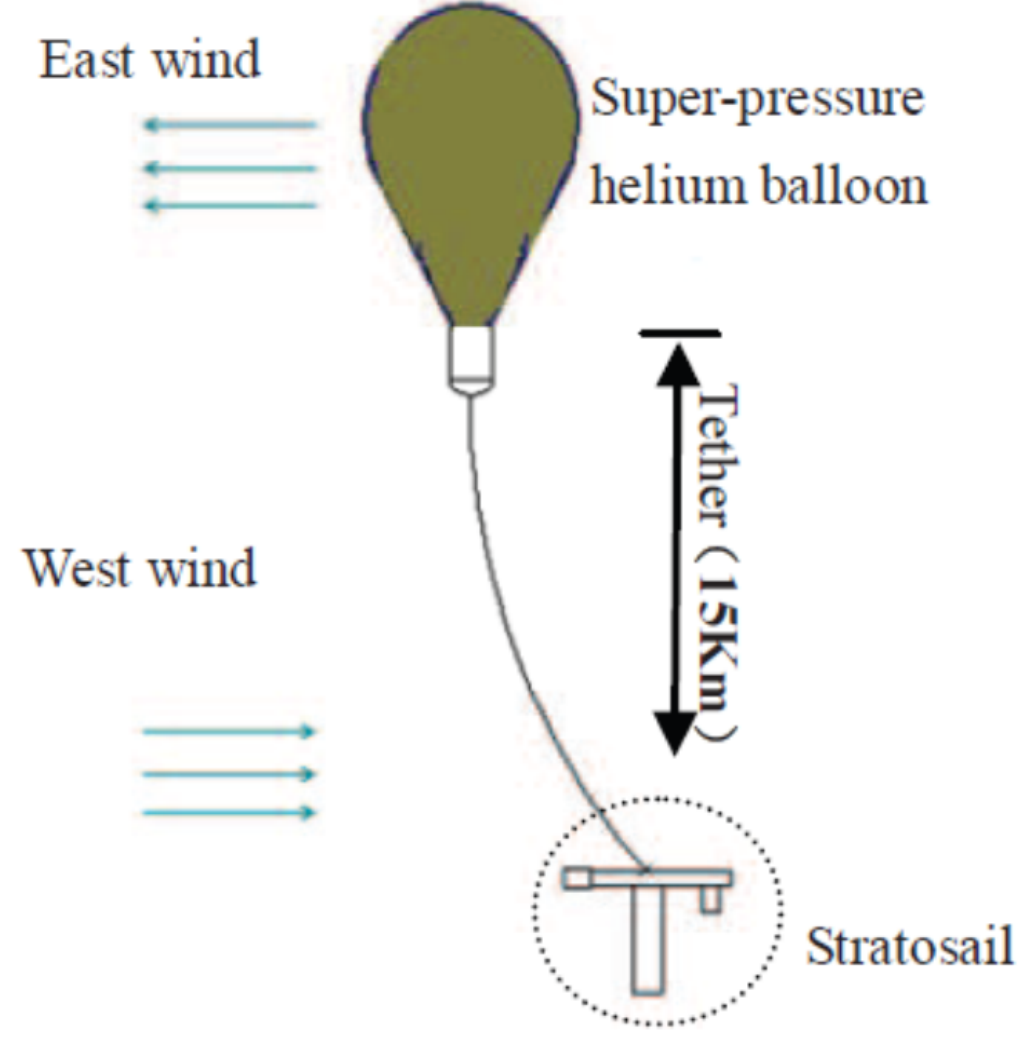

Figure 1. Schematic of a balloon system with a helium balloon and a stratosail.

As a passive device, the stratosail does not consume any power for its operation. There may be only minimal energy required to adjust the length of the tether and adjusting the angle of attack through a rudder system. This is more favorable to alternative control systems used in stratospheric balloons, which may include thrusters or a highpressure gas storage chamber and an inflatable envelope to control ascend and descend of the balloon to catch winds of the desired direction (Ref. 2).

\section{Computational Model}

The following section describes the computational model used to calculate the aerodynamic drag force on the spherical balloon and stratosail. The commercial computational fluid dynamics (CFD) software Fluent is used. The wind speeds and atmospheric properties of at various altitudes are obtained from the literature.

\section{A. Atmospheric properties and wind speed}

In order to predict the trajectory of the system, it is necessary to compute the aerodynamic forces acting on the balloon and the stratosail. These forces depend on the atmospheric properties at the stratosphere. Figure 2 shows the variation of wind speed at various altitudes; the range of interest is of the stratosphere from $10 \mathrm{~km}$ to $50 \mathrm{~km}$. The other atmospheric properties required in the calculations are given in Table 1. 


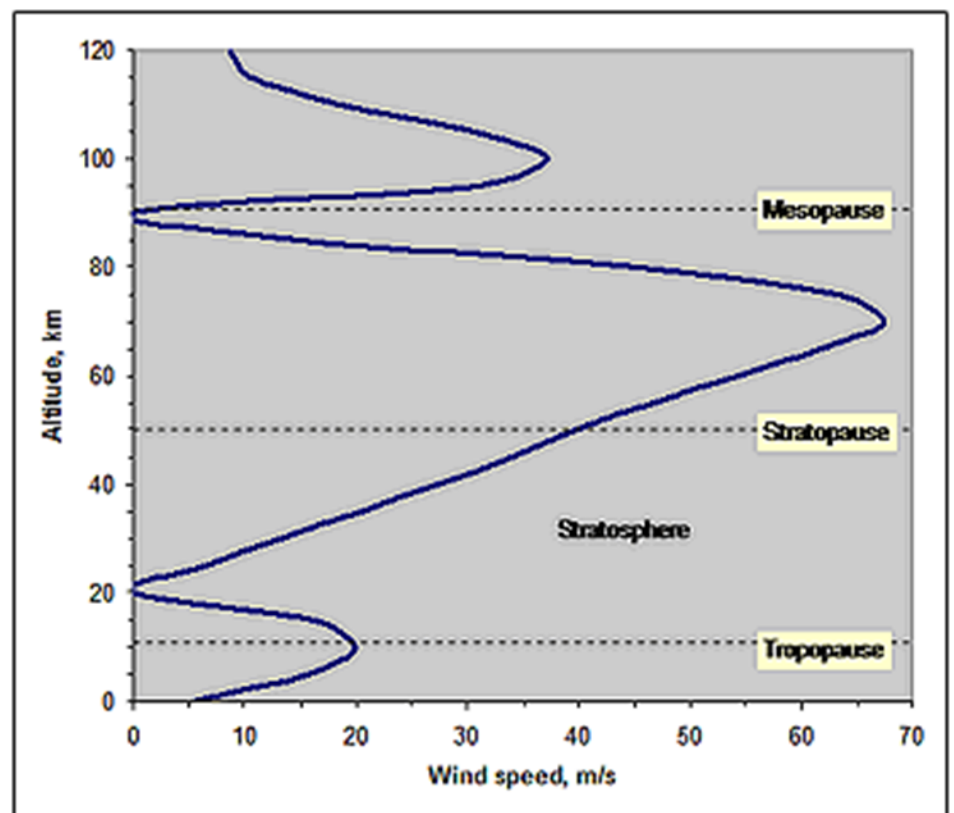

Figure 2. Plot of altitude $(\mathrm{km})$ against Wind Speed $(\mathrm{m} / \mathrm{s})($ Ref. 3$)$

Table 1. Physical Properties of U.S Standard Atmosphere, 1976 in SI Units (Ref. 4)

\begin{tabular}{|l|l|l|l|l|}
\hline Height Of Stratosphere $(\mathrm{km})$ & 45 & 40 & 30 & 15 \\
\hline Temperature of air $(\mathrm{K})$ & 265.05 & 251.05 & 226.65 & 216.65 \\
\hline Air Density $\left(\mathrm{kg} / \mathrm{m}^{3}\right)$ & $1.88 \mathrm{E}-03$ & $3.85 \mathrm{E}-03$ & $1.80 \mathrm{E}-02$ & $1.94 \mathrm{E}-01$ \\
\hline Wind Speed (m/s) & 33 & 26 & 11 & 15 \\
\hline Kinematic Viscosity (N.s) & $1.69 \mathrm{E}-05$ & $1.62 \mathrm{E}-05$ & $1.49 \mathrm{E}-05$ & $1.43 \mathrm{E}-05$ \\
\hline
\end{tabular}

\section{B. Calculation of aerodynamic drag force}

The commercial software Solidworks was used to generate a model for the stratosail based on the dimensions found on the internet: the wing assembly includes an 18 -ft long by $3.6-\mathrm{ft}$ wide wing and a 8 -ft long by 2 -ft wide rudder. The stratosail is constructed of lightweight composites, attached to a 20 -ft long tubular aluminum boom (Ref. 1). Fig. 3 shows the isometric view and the front view of the stratosail, with all dimensions labelled in millimeters.

A schematic of the computational domain with the stratosail is shown in Fig. 4 below. The commercial software Fluent is used to compute the drag force (in the z-direction) acting on the stratosail at various angles of attack $\left(0^{\circ}\right.$, $30^{\circ}, 60^{\circ}$, and $90^{\circ}$ ). The computational domain has a size of $200 \mathrm{~m} \times 100 \mathrm{~m} \times 300 \mathrm{~m}$. On the surface of the stratosail, no-slip boundary condition is prescribed. At the inlet, a prescribed parallel flow with known velocity is given, and a fully-developed flow is assumed at the outlet so that the flux for all flow variables in the exit direction are zero. Static guage pressure of zero is prescribed for the rest of the boundaries of the domain. An inflation layer option was used so that the boundary layer to be captured. The smooth transition option was used to capture the effect of boundary layer more accurately. The number of nodes and elements in the model is given in Table 2 for the various angles of attack.

The Fluent model was also used to calculate the drag force on the helium balloon, which is assumed to be spherical. This was performed to benchmark the Fluent simulation results, as expressions for solutions for drag force on a sphere are available in the literature (Ref. 5). 


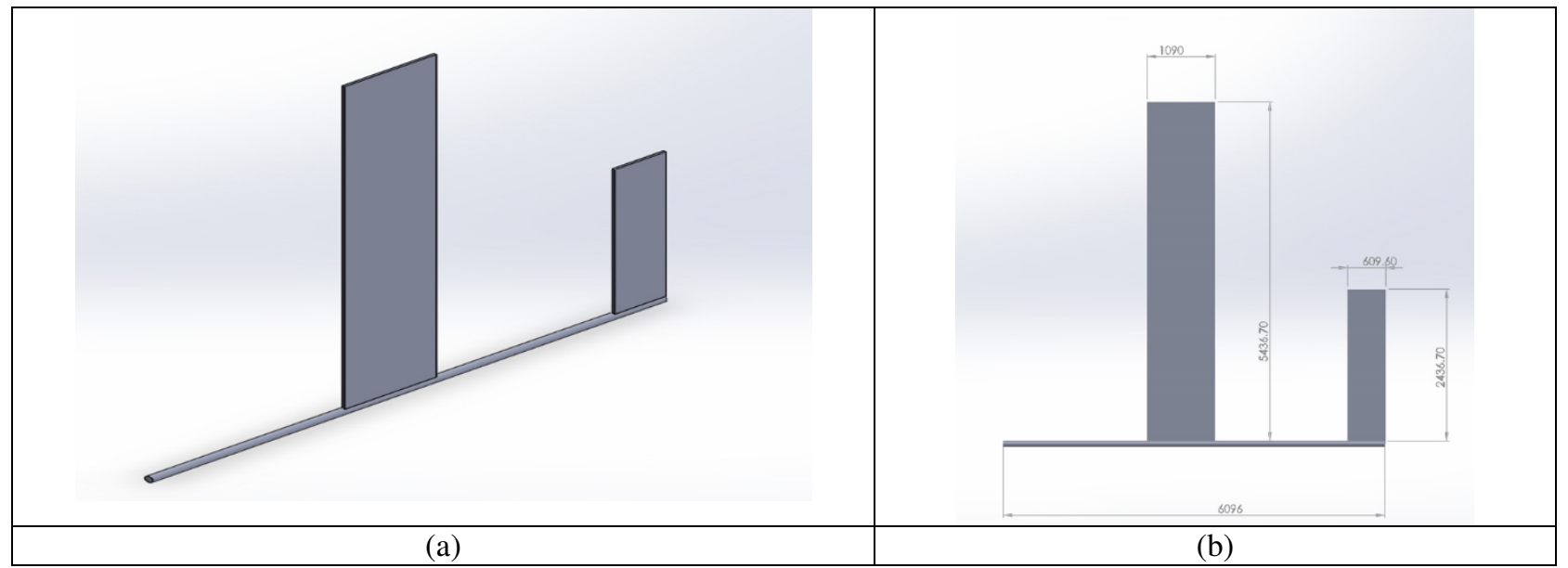

Figure 3. Solidworks model of the startosail.
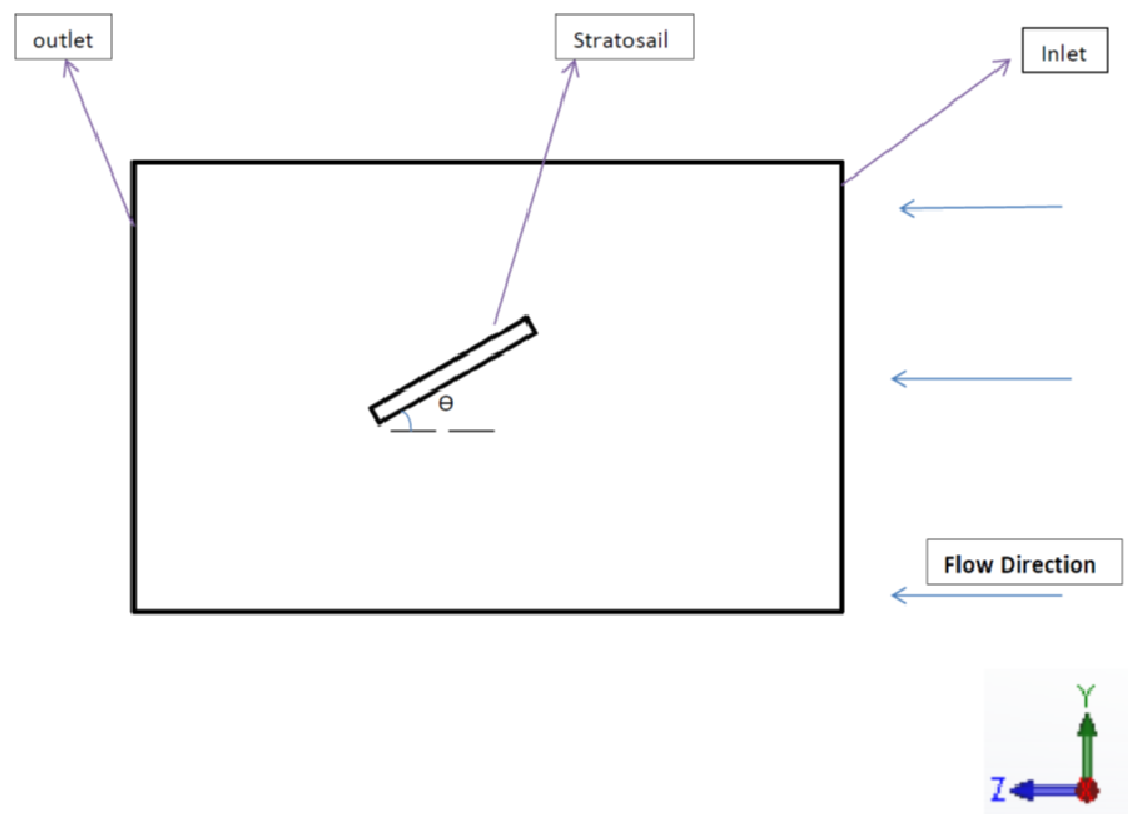

Figure 4. Computational domain for stratosail using the Fluent software.

Table 2. Mesh Size for Stratosail Simulation

\begin{tabular}{|l|l|l|}
\hline Angle of Orientation & Nodes & Elements \\
\hline 0 degrees & 77208 & 403512 \\
\hline 30 degrees & 77329 & 403376 \\
\hline 60 degrees & 76948 & 401424 \\
\hline 90 degrees & 78130 & 406841 \\
\hline
\end{tabular}




\section{Calculation of drift velocity}

After obtaining the drag forces on the stratosail and balloon under various conditions (altitude, air speed, angle of attack), the drift velocity of the system with the balloon and stratosail tethered together is determined. For simplicity of calculations, this drift velocity is calculated for given altitudes of the balloon and stratosail.

As the drag forces depend on the drift velocity in a nonlinear manner, an iterative scheme was used to calculate the steady-state drift velocity. An initial drift velocity is assumed, and the drag forces on the balloon and stratosail are calculated and compared. If the drag forces are no equal and opposite, the drift velocity is adjusted until equilibrium is reached. Fig. 5 shows the flowchart that outlines the iterative process of computing the drift velocity.

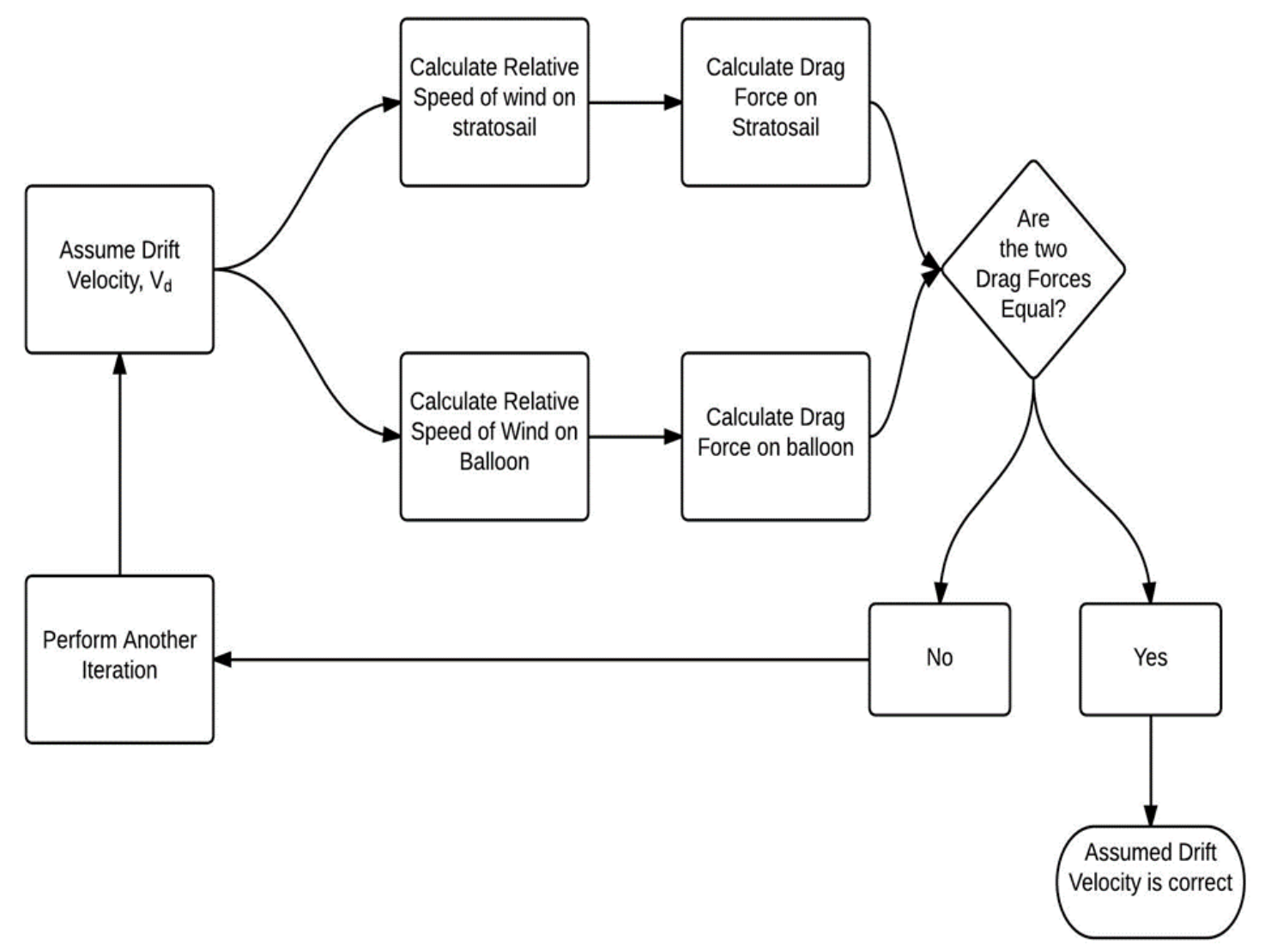

Figure 5. Flowchart for iteration process for calculating the drift velocity of the balloon-stratosail system. 


\section{Calculation of the length of tether}

Finally, the length of the tether required to maintain the given altitudes of the balloon and stratosail are calculated. This is obtained by considering the vertical equilibrium of the system (Fig, 6) and taking into account the weight of the tether (26 lbs. per 9 mile) using the catenary cable equation.

$$
\begin{aligned}
& y=\frac{T_{0}}{w} \cosh \left(\frac{w z}{T_{0}}\right) \\
& s=\frac{T_{0}}{w} \sinh \left(\frac{w z}{T_{0}}\right)
\end{aligned}
$$

where $w$ is the weight per unit length of the cable, $T_{0}$ is the horizontal tension at the lowest point of the catenary cable system. The coordinates $(y, z)$ are the height and horizontal distance and $s$ is the length of the cable, all measured from the lowest point of the catenary cable.

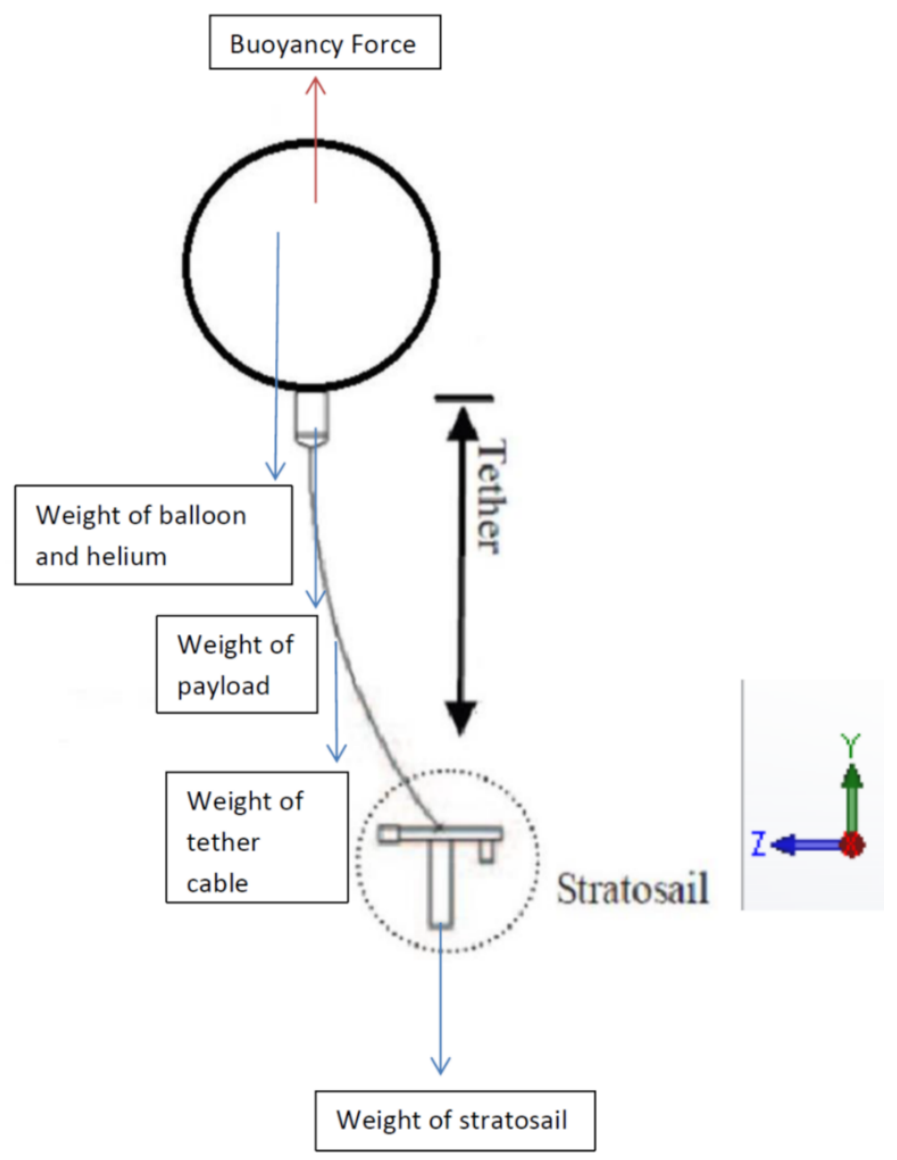

Figure 6. Vertical equilibrium of the balloon-stratosail system 


\section{Results}

In this section, we present the results on simulation results using the Fluent software to obtain the aerodynamic drag force acting on the stratosail. With the drag forces acting on the stratosail and balloon, the steady state drift velocity of the system (under opposing winds) was obtained by considering force balance. The length of the tether was also calculated for the cases that were investigated.

\section{A. Validation of Fluent simulation}

For validation, the drag force on a sphere is computed using the Fluent software for Reynold's number from 1 to $10^{6}$. The drag coefficient $\left(\mathrm{C}_{\mathrm{d}}\right)$ results are compare against experimental data reported in the textbook (Ref. 5), as shown in Fig. 7. The laminar model is used for Reynold's number from 1 to $10^{4}$, while the Shear Stress Transport (SST) K-omega model for $10^{4}$ to $10^{6}$. The numerical simulation gives reasonably good agreement with the data reported in the textbook.

Small differences are noticed when the inflation option is turned on to allow a smooth transition of the elements. In the regions near to the surface of the sphere, there is a large change in velocity normal to the surface. As such, it is important to capture this gradient accurately, and the inflation layer option allows the boundary layer to be captured to give more accurate results.

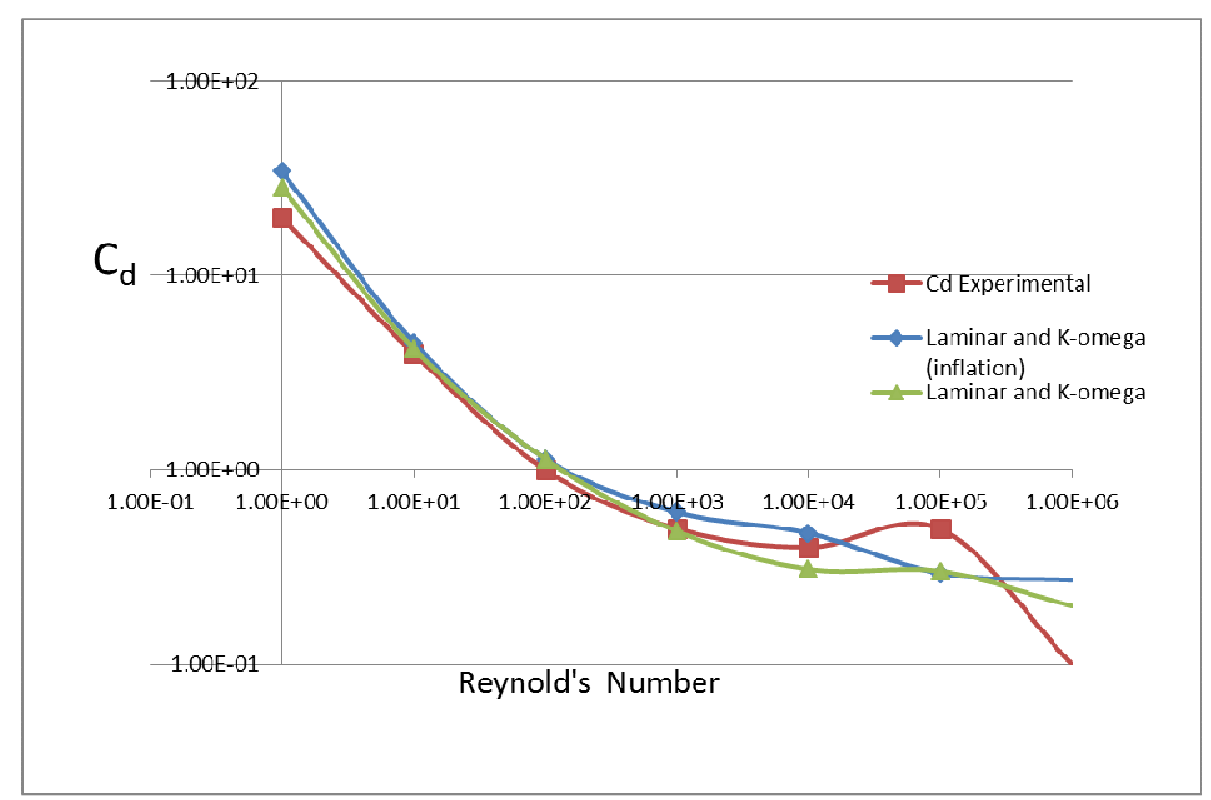

Figure 7. Plot of drag coefficient against Reynold's number for a sphere.

\section{B. Drag force acting on stratosail}

Having validated the Fluent simulation for the spherical balloon, the drag force acting on the stratosail is calculated. Fig. 8 below shows the variation of the drag force on a stratosail at $15 \mathrm{~km}$ altitude at an angles of attack of $90^{\circ}$ and $60^{\circ}$ for various relative air speeds. It can be seen that the drag force increases with the relative air speed. The drag force is also larger at a larger angle of attack, as the frontal area of the stratosail increases with the angle of attack (maximum at $90^{\circ}$ ).

American Institute of Aeronautics and Astronautics 


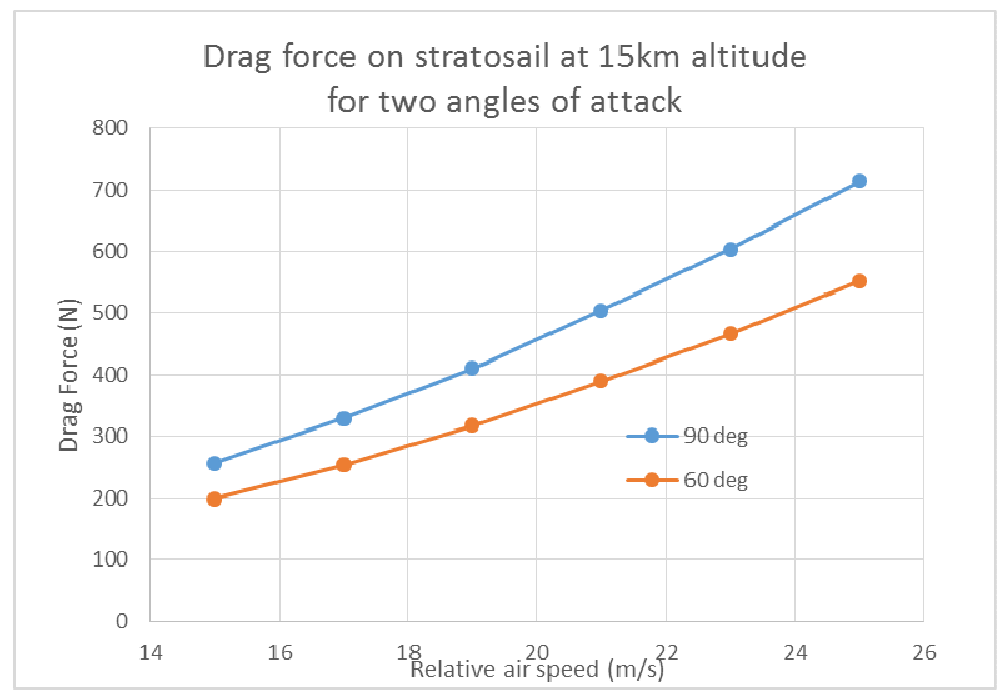

Figure 8. Drag force on stratosail against relative air speed.

\section{Drift velocity of balloon system}

With the profile of drag forces against the air speed for the spherical balloon and stratosail, we obtain the steady state drift velocity of the balloon-stratosail system. The calculation assumed the best case scenario that the winds on the stratosail and the balloon are in opposing directions.

Fig. 9 shows the drift velocity of the system for the case where the balloon is at an altitude of 30km (air speed about $12.5 \mathrm{~m} / \mathrm{s}$ ) and the stratosail at an altitude of $15 \mathrm{~km}$ (air speed about $15 \mathrm{~m} / \mathrm{s}$ ) with an angle of attack of $90^{\circ}$. It was observed that the drift velocity is reduced to less than $2 \mathrm{~m} / \mathrm{s}$ for various sizes of the balloon. Without the stratosail, the balloon would attain the air speed of $12.5 \mathrm{~m} / \mathrm{s}$ at $30 \mathrm{~km}$. If the stratosail is able to catch the opposite wind at $15 \mathrm{~km}$, the system drift speed is significantly lower. If the wind at $15 \mathrm{~km}$ is not opposite to that at $30 \mathrm{~km}$, the stratosail will be less effective and should be retracted if the winds are in the same direction. As expected, a larger balloon size results in a larger drift velocity as the drag force on the balloon increases with its size, while the drag force on the stratosail remains unchanged.

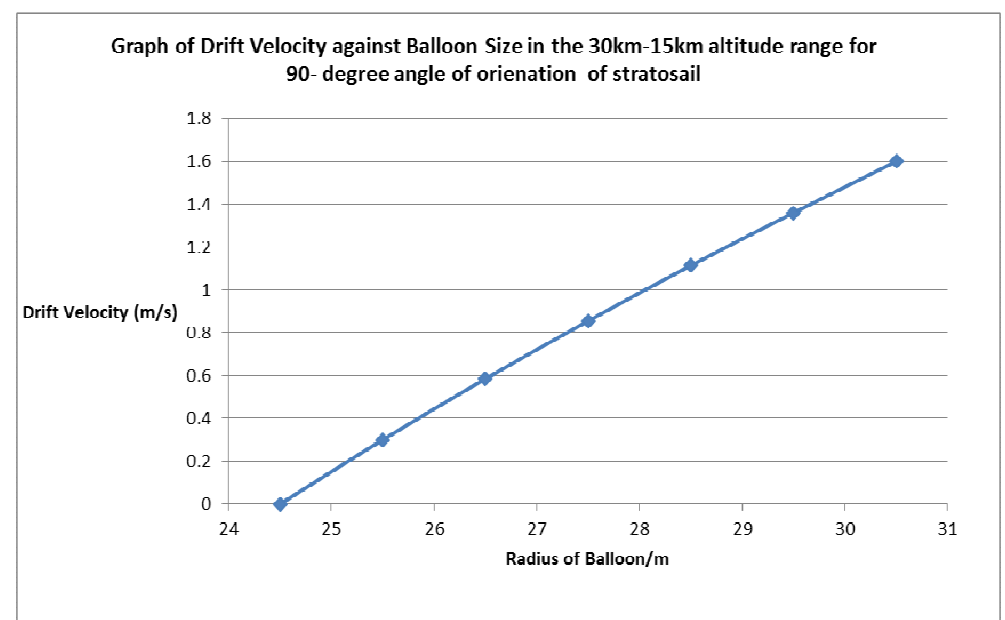

Figure 9. Drift velocity against balloon size in the $30 \mathrm{~km}-15 \mathrm{~km}$ altitude range for $90^{\circ}$ angle of attack

American Institute of Aeronautics and Astronautics 
The drift velocity is also calculated for two other altitudes of the stratosail at $20 \mathrm{~km}$ and $25 \mathrm{~km}$, as shown in Fig. 10. As with the previous case, the drift velocity increases with the radius of the balloon. Among all the three cases, the drift velocity is highest when the stratosail is placed at $20 \mathrm{~km}$ since the wind speed is minimum at that altitude.

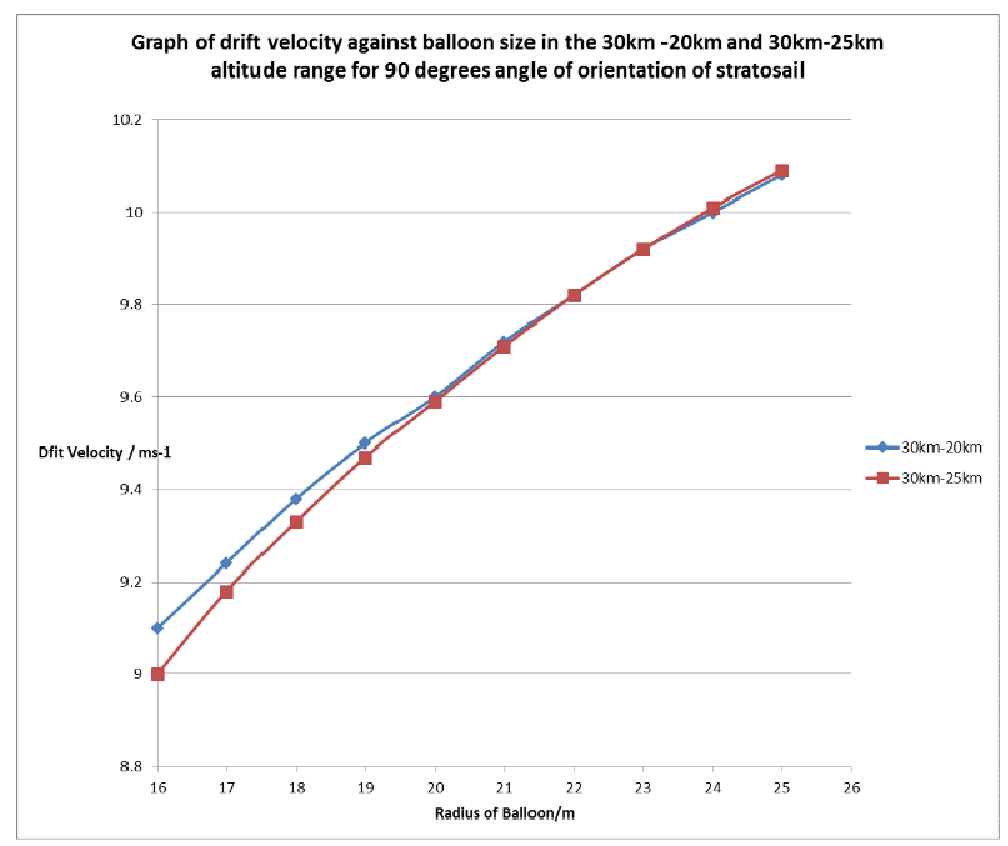

Figure 10. Drift velocity against balloon size in the $30 \mathrm{~km}-20 \mathrm{~km}$ and $30 \mathrm{~km}-25 \mathrm{~km}$ altitude range for $90^{\circ}$ angle of attack

Fig. 11 shows a comparison of the drift velocity when the angle of attack is reduced to $60^{\circ}$ for the case of balloon at $30 \mathrm{~km}$ and stratosail at $15 \mathrm{~km}$. At a $60^{\circ}$ angle of attack, the drag force experienced by the stratosail is lower than that at $90^{\circ}$ for the same range of relative speeds, due to the smaller effective cross-sectional area of the stratosail at $60^{\circ}$. Therefore, a higher drift velocity is recorded for a lower angle of attack.

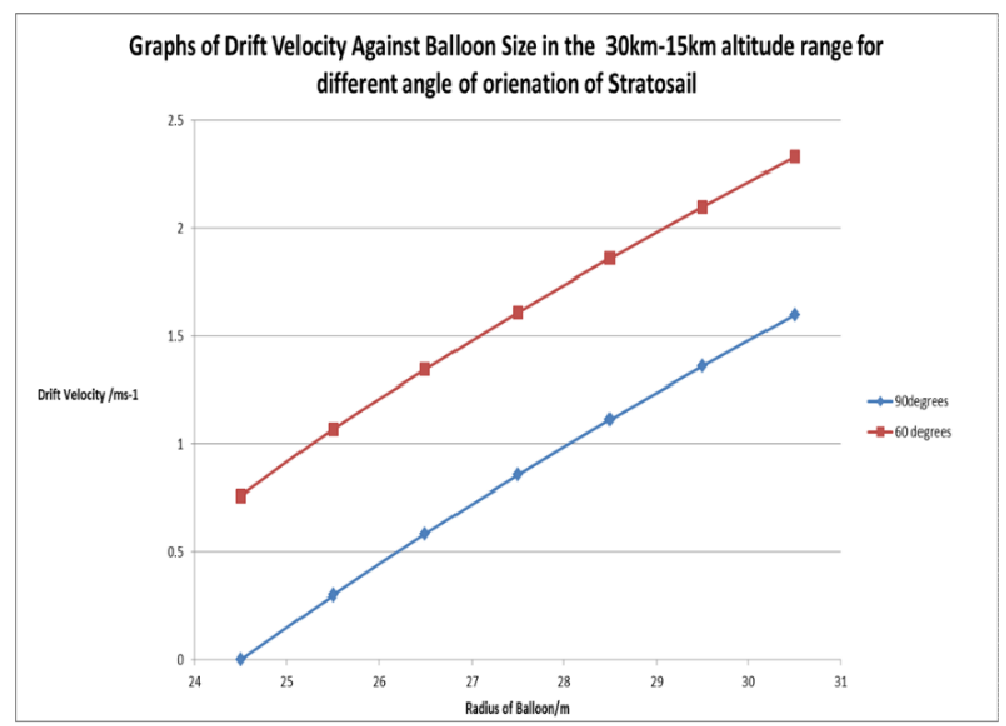

Figure 11. Comparison of drift velocity of system for two angles of attack $\left(90^{\circ}\right.$ and $\left.60^{\circ}\right)$.

American Institute of Aeronautics and Astronautics 


\section{Tether length}

For the system to attain the drift velocity at the desired altitudes, the length of the tether needs to be determined. Based on the catenary cable equations (1) and (2), the length of the tether for various cases of altitudes and angles of attack are obtained and plotted in Fig. 12. From the plots, it can be seen that the length of tether increases with the size of the balloon. This is due to the increase in the parameter $\mathrm{T}_{0}$ in the catenary equation, and this parameter is given by the horizontal drag force (larger balloon radius gives larger drag force).

Also, the stratosail oriented at an angle of attack of $90^{\circ}$ generates a higher drag force compared to $60^{\circ}$; thus, the tether length is also longer for the case of $90^{\circ}$ for a given size of the balloon and altitudes of the balloon and stratosail.

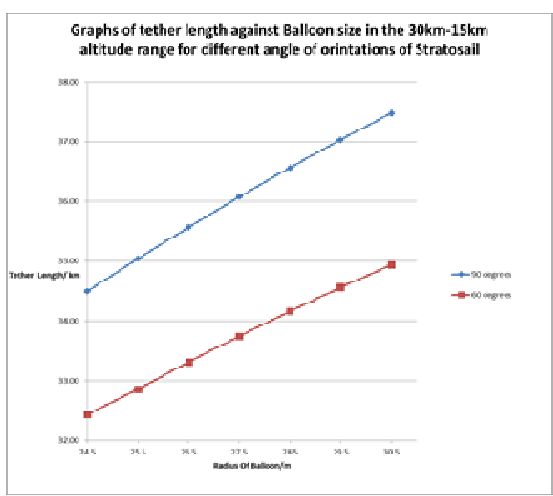

(a)

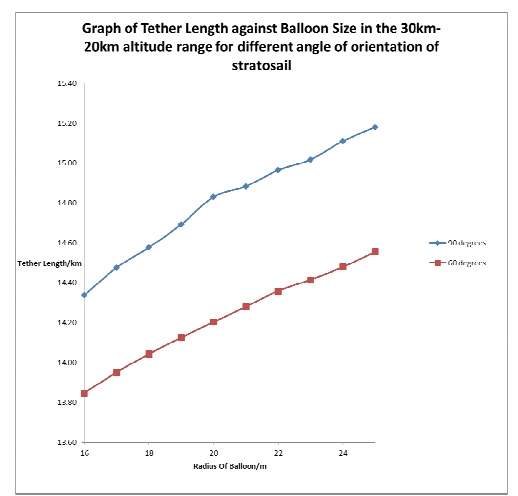

(b)

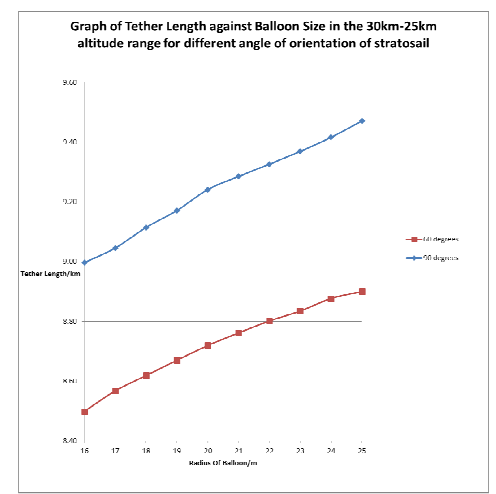

(c)

Figure 12. Tether length for various balloon sizes and angles of attack.

\section{Conclusion and Future Work}

In this paper, we presented some preliminary results on investigating the dynamics and motion of a balloonstratosail system. This is the initial stage of a study on the station-keeping capability of a stratosphere balloon system using a passive stratotsail device. The simulations are kept to a two-dimensional plane, and only the steadystate linear drift velocity was calculated. Also, the ideal situation of opposing winds at the two altitudes of the balloon and stratosail was assumed.

With this preliminary study, we hope to extend our study to more realistic cases. Full three-dimensional and transient simulations and analysis will be carried out in the future. We have acquired historical data of the wind speeds and directions at various altitudes, and these will be used as the inputs for the model. The tether length will also be used an input to the model to control the trajectory of the balloon stratosail system. By changing the tether length, the altitude of the stratosail will be adjusted to catch the appropriate wind direction for reducing the drift of the system. With such improvement in the model, we will be able to simulate and evaluate control strategies to achieve the station-keeping ability of such a stratospheric balloon system.

\section{References}

${ }^{1}$ Global Aerospace Corporation, "StratoSail(R) Balloon Guidance System",

URL: http://www.gaerospace.com/projects/ULBDStratoSail/ULDB_balloon_trajectory.html [cited 24 May 2015].

${ }^{2}$ Richard Wayne DeVaul, E. T. (2014). Patent No. US20140048646 Ā1. United States.

${ }^{3}$ Struzak, R. "Mobile telecommunications via stratosphere" Intercomms - International Communications Project, 2003 , 1-20.

${ }^{4}$ Braeunig, R. A. URL: http://www.braeunig.us/space/atmos.htm [cited 24 May 2015].

${ }^{5}$ Kumar, K. (2010). Engineering Fluid Mechanics. S Chand \& Co Ltd. 